\title{
Association of body mass index with carpal tunnel syndrome
}

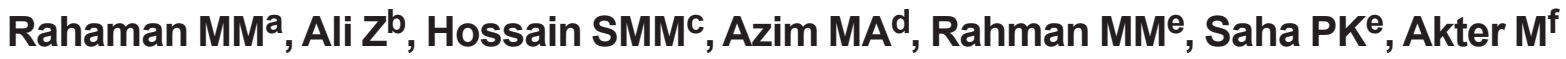

\begin{abstract}
Background: Carpal tunnel syndrome (CTS) is a chronic disabling condition of hands, occurring due to occupational and non-occupational risk factors, including high body mass index (BMI). This study was intended to find out the association of BMI with CTS.
\end{abstract}

Methods: This was a cross-sectional analytical study was conducted in four teaching hospitals in Dhaka, Bangladesh from June 2017 to May 2018. Patients with electrophysiologically documented CTS were taken as cases and age matched healthy individuals without CTS were taken as controls. Following clinical and electrodiagnostic confirmation, data were collected from total 63 patients and 63 controls.

Results: Mean BMI was $29.3 \pm 4.8 \mathrm{Kg} / \mathrm{m}^{2}$ in CTS group, which was higher than the control $\left(24.1 \pm 3.3 \mathrm{Kg} / \mathrm{m}^{2}\right)$. In CTS group, 56 (88.9\%) had high BMI and 7 (11.1\%) had normal BMI. On the other hand. 23 (36.9\%) subjects in control group had high BMI and 40 (63.1\%) had normal BMI. High BMI was significantly associated with carpal tunnel syndrome $(p<0.01)$ but ncreasing BMI was not associated with severity of CTS ( $p 0.654)$.

Conclusion: High BMI has a significant association with CTS but not with CTS severity.

Key words: association, body mass index, carpal tunnel syndrome.

(BIRDEM Med J 2021; 11(3): 179-185)

\section{INTRODUCTION}

Carpal tunnel syndrome (CTS) is the most common form of entrapment neuropathy. On the basis of clinical examinations and nerve conduction studies (NCS), it has been approximated that one in every five subjects who complains of symptoms such as pain, numbness and a tingling sensation in the hands could have CTS. ${ }^{1}$ First described by Paget in 1854, CTS remains a puzzling and disabling condition commonly presented to rheumatologists, neurologist and orthopedicians. ${ }^{2}$ It is a compressive neuropathy, caused by entrapment of the median nerve at the level of the carpal tunnel, delimitated by the carpal bones and by the transverse carpal ligament. ${ }^{3}$ The American Academy of Orthopaedic Surgeons (AAOS) Clinical Guidelines on the Diagnosis of CTS defines it as a symptomatic compression neuropathy of the median nerve at the level of the wrist. ${ }^{4}$ Primary features of CTS include pain in the hand, unpleasant tingling, pain or numbness in the distal distribution of the median nerve and a reduction of the

\section{Author information}

a. Md. Motiur Rahaman, Senior Medical Officer, Department of Gastroenterology, Hepatobiliary and Pancreatic Diseases, BIRDEM General Hospital, Dhaka, Bangladesh.

b. Zahed Ali, Professor and Head, Department of Neurology, Sir Salimullah Medical College, Dhaka, Bangladesh.

c. SM Monowar Hossain, Assistant Professor, Department of Neurology, US Bangla Medical College, Narayangonj, Bangladesh.

d. Muhammad Arshad-ul Azim, Assistant Professor (OSD), Department of Nephrology, Shahid Sheikh Abu Naser Specialized Hospital, Khulna, Bangladesh.

e. Md. Moshiur Rahman, Pallob Kanti Saha, Assistant Professor, Department of Neurology, Sir Salimullah Medical College, Dhaka, Bangladesh.

f. Mafia Akter, Senior Medical Officer, Department of Neurology, BIRDEM General Hospital, Dhaka, Bangladesh.

Address of correspondence: Md. Motiur Rahaman, Senior Medical Officer, Department of Gastroenterology, Hepatobiliary and Pancreatic Diseases, BIRDEM General Hospital, Dhaka, Bangladesh. Email: motiur92@hotmail.com

Received: July 12, 2020

Revision received: July 3, 2021

Accepted: July 31, 2021 
grip strength and function of the affected hand. ${ }^{5}$ In most cases, where the complaints and findings are typical, the diagnosis of CTS is relatively easy. However, this is not always the case. NCSs are the most common tests used to assess the function of the median nerve. These studies usually comprise measuring motor distal latency, compound muscle action potential, sensory nerve conduction velocity (SCV) and sensory nerve action potential. Electrodiagnostic findings can confirm median nerve entrapment, but needs considerable expertise. ${ }^{6,7}$

Body mass index (BMI) has been attributed as a risk factor for the development of CTS. ${ }^{8}$ It has been found that a recent gain in weight is a risk factor for CTS because of increased fluid accumulation in the tissue spaces in the carpal tunnel. ${ }^{9,10}$ An obese individual had 2.5 times higher probability of CTS as compared to a slender individual with a mean BMI of 28.9 and 26.2, respectively. ${ }^{11}$ Geoghegan et al. in their study found that obesity was an important risk factor associated with CTS. ${ }^{12}$

There is very limited statistics regarding prevalence of CTS and its association with obesity in Bangladesh. A recent study showed that $18.9 \%$ of adult populations in Bangladesh are overweight and $4.6 \%$ are obese. ${ }^{13}$ Obesity is subject to modification by lifestyle interventions. Along with other complications of obesity like diabetes, hypertension, dyslipidaemia etc. CTS is an important and disabling condition. Therefore, this study aimed to evaluate the association of BMI with CTS in tertiary level hospitals in Bangladesh.

\section{METHODS}

This cross-sectional analytical study was carried out from June 2017 to May 2018 in the Departments of Neurology of Sir Salimullah Medical College \& Mitford Hospital (SSMC \& MH), Dhaka Medical College Hospital (DMCH), Bangabandhu Sheikh Mujib Medical University (BSMMU) and National Institute of Neuroscience (NINS). Convenience sampling method was used. Minimum sample size was calculated to be 54 by assuming a prevalence of 3.8\%. ${ }^{1}$ We included 63 patients and 63 controls in the study.

Patients over 18 years of age (both male and female) having clinical features and electrophysiologic findings compatible with CTS were included as cases. Patients with cervical spondylotic radiculopathy, diabetes mellitus, hypothyroidism, rheumatoid arthritis, pregnancy, motor neuron disease, myopathies, muscular dystrophies, neuromuscular junction disorders, acute confusional state, edema, prosthetic device etc. which can interfere with electrophysiological investigations were excluded. Age and sex matched healthy individuals, not having CTS clinically or electrophysiologically were taken as controls.

\section{Study procedure}

A detailed questionnaire was filled out for each case, with a view of detecting symptoms and signs of CTS, excluding confounding factors that might have affected NCS results. Detailed family history, treatment and medical history was taken with physical and clinical examination. Clinical assessments were carried out by one examiner on all patients, focusing specifically on sensory deficits and motor weakness in the distribution of median nerve.

NCS was performed with standard surface stimulation and recording techniques on a Neuropack S1 four channel electromyography (Nihon Kohden Co. Japan) with standard filter settings and a surface stimulator using a $0.1 \mathrm{~ms}$ square-wave pulse.

Motor nerve-conduction studies were performed by bilateral studies of both ulnar and median nerves including $\mathrm{F}$ waves in the upper limb. Measurement of muscle-action potential amplitude and latency at each site of stimulation and calculation of segmental conduction velocity was done. Sensory nerveconduction studies were performed by bilateral studies of both ulnar and median nerves. Measurement of nerveaction potential amplitude and latency at each site of stimulation and calculation of segmental conduction velocity were done. Studies of additional nerves were done when necessary, to characterize abnormalities based on the distribution of clinical symptoms or signs.

For motor NCS gain was kept at $2 \mathrm{mV} /$ division, time sweep at $2 \mathrm{~ms} /$ division and low and high frequency filters at 10 and $32 \mathrm{kHz}$ respectively, while for sensory studies gain was at $20 \mathrm{iV} /$ division and time sweep at 1 $\mathrm{ms} /$ division with the same filter settings. Compound muscle action potential amplitudes were measured from the baseline to negative peak and onset latencies were measured for distal and proximal stimulation sites. Sensory nerve action potential (SNAP) amplitude were measured from the initial positive peak to the negative 
peak or from the baseline to the negative peak if there was no initial positive peak. The results were calculated on the basis of average of ten or more responses.

Conduction velocities were calculated from the onset latency and distance measurements. Motor conduction velocities were determined for the median nerve and ulnar nerve and calculated by dividing the distance between proximal and distal stimulating cathodes by the latency. Sensory conduction velocity was calculated by dividing the distance between stimulating and recording electrodes by response latency.

\section{Data collection technique}

Data were collected using a semi-structured questionnaire by the investigator. Face to face interview, medical history, clinical examination and relevant laboratory investigations were done.

\section{Statistical analysis}

Data analysis was carried out by using the Statistical Package for Social Sciences (SPSS) software version 22.0 for Windows. The Chi-square test and was used to evaluate the proportions. A p value $<0.05$ was considered as statistically significant.

\section{Ethical considerations}

Ethical clearance was taken from the Institutional Review Board, SSMC \& MH. All the patients were informed about the type and nature of the study and informed written consent was taken before collecting data. Proper permission was taken from the concerned departments. Interest of the study subjects was not compromised. All the study subjects were assured of adequate treatment of any complications developed in relation to the study process. Subjects were assured about their confidentiality and freedom to withdraw at any time. Written consent in Bangla and English was taken free of duress and without exploiting any weakness of the subject.

\section{RESULTS}

A total of 89 patients with CTS (clinically and electrophysiologically diagnosed) were initially enrolled and from them 26 were excluded due to different reasons. Data were collected from the remaining 63 cases. Sixty three age and sex matched persons without CTS were taken as controls. The mean age of the CTS group was $47.2 \pm 12.5$ years, while that of control group was $46.4 \pm 14.9$ years. Male: female ratio was 1:1.6 in CTS group and $1: 1.2$ in control group. Mean BMI was $29.3 \pm 4.8 \mathrm{Kg} / \mathrm{m}^{2}$ in CTS group and $24.1 \pm 3.3 \mathrm{Kg} / \mathrm{m}^{2}$ in controls.
The predominant presenting symptoms were pain (59, $93.7 \%)$, paresthesia $(52,82.5 \%)$, tingling $(63,100 \%)$ and numbness $(47,74.6 \%)$ (Table I). Neurological examination findings, laboratory parameters and NCS findings are shown in Tables II, III and IV respectively.

Table I Clinical features of the study subjects with $\mathrm{CTS}(\mathrm{N}=63)$

\begin{tabular}{lc}
\hline Presentation & $\mathrm{n}(\%)$ \\
\hline Pain & $59(93.7)$ \\
Paresthesia & $52(82.5)$ \\
Tingling & $63(100.0)$ \\
Numbness & $47(74.6)$ \\
Cramps in upper limb muscles & $14(22.2)$ \\
Weakness of hand and fingers & $19(30.2)$ \\
\hline
\end{tabular}

*Multiple responses

Table II Neurological examination findings in the affected limb of the study subjects with CTS ( $\mathrm{N}=63)$

\begin{tabular}{lc}
\hline Parameter & $\mathrm{n}(\%)$ \\
\hline Wasting of thenar muscles & $41(65.1)$ \\
Weakness of opposition of thumb & $46(73.0)$ \\
Diminished pain sensation in median & $59(93.7)$ \\
nerve distribution & \\
$\begin{array}{l}\text { Diminished fine touch sensation in } \\
\text { median nerve distribution }\end{array}$ & $56(88.9)$ \\
Positive Tinel's sign & \\
Positive Phalen's sign & $34(54.0)$ \\
\hline
\end{tabular}

Table III Laboratory parameters of study subjects with CTS ( $\mathrm{N}=63)$

\begin{tabular}{lc}
\hline Investigation & Mean \pm SD \\
\hline $\mathrm{Hb}(\mathrm{gm} / \mathrm{dL})$ & $12.3 \pm 2.27$ \\
$\mathrm{WBC}$ count $\left(\right.$ per mm $\left.{ }^{3}\right)$ & $8340 \pm 2533$ \\
$\mathrm{ESR}\left(\mathrm{mm}\right.$ in $1^{\text {st }}$ hour $)$ & $28.2 \pm 13.4$ \\
Fasting blood glucose $(\mathrm{mmol} / \mathrm{L})$ & $5.8 \pm 1.86$ \\
Blood urea $(\mathrm{mg} / \mathrm{dL})$ & $26.4 \pm 9.31$ \\
Serum creatinine $(\mathrm{mg} / \mathrm{dL})$ & $0.93 \pm 0.17$ \\
Serum ALT $(\mathrm{u} / \mathrm{L})$ & $48.3 \pm 18.8$ \\
$\mathrm{FT}_{4}(\mathrm{pmol} / \mathrm{L})$ & $14.7 \pm 4.65$ \\
$\mathrm{TSH}(\mu \mathrm{IU} / \mathrm{mL})$ & $2.9 \pm 1.08$ \\
\hline
\end{tabular}


Table IV Findings of nerve conduction study in patients with CTS $(\mathrm{N}=63)$

\begin{tabular}{ll}
\hline $\begin{array}{l}\text { Median nerve } \\
\text { conduction study }\end{array}$ & Mean \pm SD (Range) \\
\hline Motor & \\
MNCV $(\mathrm{m} / \mathrm{s})$ & $37.63 \pm 16.76(12.30-83.40)$ \\
$\mathrm{DL}(\mathrm{msec})$ & $6.54 \pm 1.71(5.16-11.55)$ \\
$\mathrm{CMAP}(\mathrm{mV})$ & $4.82 \pm 2.37(0.62-14.92)$ \\
Sensory & \\
SNCV $(\mathrm{m} / \mathrm{s})$ & $36.60 \pm 7.38(20.30-58.90)$ \\
$\mathrm{DL}(\mathrm{msec})$ & $3.72 \pm 0.67(3.34-5.40)$ \\
$\mathrm{SNAP}(\mu \mathrm{V})$ & $16.59 \pm 8.43(3.10-37.50)$ \\
\hline
\end{tabular}

In the CTS group, 7 (11.1\%) were having normal BMI and 56 (88.9\%) were having abnormal BMI [27 (42.9\%) were overweight, 24 (38.1\%) were obese, 5 (7.9\%) were morbidly obese]. In control group, 40 (63.1\%) had normal BMI 23, 36.9\%) had high BMI [17 (27.7\%) were overweight, $5(7.7 \%)$ were obese and $1(1.5 \%)$ was morbidly obese]. BMI was significantly associated with CTS $\left(p<0.00001, d f=3, \chi^{2}\right.$ value 40.977) $($ Table V).

Table V Association of high BMI with CTS ( $\mathrm{N}=128)$

\begin{tabular}{lccc}
\hline & CTS & No CTS & p value \\
\hline High BMI & 56 & 24 & $<0.01$ \\
Normal BMI & 7 & 41 & \\
Total & 63 & 65 & \\
\hline
\end{tabular}

Derived by $\chi^{2}$ test. $\chi^{2}$ value 36.8611

Eight (12.7\%) patients had symptoms for less than 4 weeks, 18 (28.6\%) had 4 to 8 weeks and $37(58.7 \%)$ had symptoms for more than 8 weeks. Duration of symptoms had relation with CTS severity (Table VI).

Table VI Association of duration of illness with severity of CTS (N=63)

\begin{tabular}{lccccc}
\hline Duration & Mild CTS & Moderate CTS & Severe CTS & Total & p value \\
\hline Acute & 5 & 2 & 1 & 8 & 0.031 \\
Subacute & 3 & 8 & 7 & 18 & \\
Chronic & 7 & 9 & 21 & 37 & \\
\hline Total & 15 & 19 & 29 & 63 & \\
\hline
\end{tabular}

Derived by $\chi^{2}$ test. $\chi^{2}$ value 10.5716 . df 4 .

With regard to association of severity of CTS with increasing BMI, it was found that, of the 29 patients with severe CTS, only 1 was of normal BMI. Twelve patients were overweight, 13 obese and 3 morbidly obese. Among the patients with moderately severe CTS,

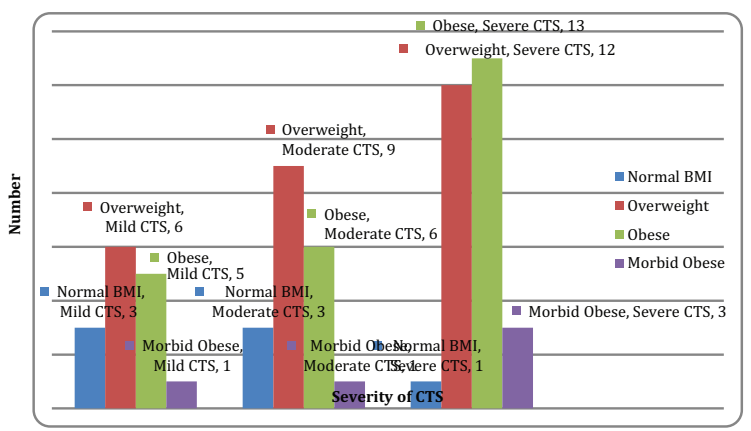

Figure 1 Categorization of severity of CTS according to $\mathrm{BMI}(\mathrm{N}=63)$
3 were of normal BMI, 9 were overweight, 6 obese and 1 morbidly obese. Only one of the patients with mild CTS was morbidly obese. Despite this, increasing BMI was not associated with severity of CTS $(p=0.654, d f=6, \div 2$ value 4.1667) (Figure 1).

\section{DISCUSSION}

This was a cross sectional analytical study done in a tertiary level hospital on the patients with clinically and electrophysiologically documented carpal tunnel syndrome to find out the association of high BMI with CTS. Total participants were 126 , with 63 CTS patients and 63 age matched controls.

Regarding age distribution of the study population, mean age was 47.2 years. The study by Mansoor et al. found that in the 112 CTS patients, age range was 38-63 years and mean age was $54 \pm 5$ years. Two patients $(2 \%)$ were in the age group of $31-40$ years, 24 patients (21\%) 
were in the age group of $41-50$ years, 75 patients (67\%) were in the age group of 51-60 years, and 11 patients $(10 \%)$ were in the age group of 61-65 years. ${ }^{8}$ Werner et al. found that mean age of patients with CTS was 46.1 years. ${ }^{9}$ Becker et al. found that age of CTS patients varied from 18 to 87 years, with a mean of 49.1 and a median of 49 years. ${ }^{10}$ All these data correspond with our findings.

Among the study population with CTS, two-thirds were female. Female predominance has been reported in previous studies on CTS. Lam et al. found male:female ratio 1:2.4 in their study. Becker et al. found male:female ratio 1:7.4. ${ }^{14}$ Karpitskaya et al. also found male: female ratio $1: 1.48$ in their study. ${ }^{15}$

Ibrahim et al. summarized that primary features of CTS include pain in the hand, unpleasant tingling, pain or numbness in the distal distribution of the median nerve (thumb, index, middle finger and the radial side of the ring finger), and a reduction of the grip strength and function of the affected hand. Symptoms tend to be worse at night, and clumsiness is reported during the day with activities requiring wrist flexion. ${ }^{16}$

Motor nerve conduction study of the study subjects showed that mean motor nerve conduction velocity (MNCV) was $37.63 \pm 16.76 \mathrm{~m} / \mathrm{sec}$, mean distal latency (DL) was $6.54 \pm 1.71 \mathrm{msec}$ and mean compound muscle action potential (CMAP) was $4.82 \pm 2.37 \mathrm{mV}$. On sensory nerve conduction study, sensory nerve conduction velocity (SNCV) was $36.60 \pm 7.38 \mathrm{~m} / \mathrm{sec}$, distal latency (DL) was $3.72 \pm 0.67 \mathrm{msec}$ and sensory nerve action potential (SNAP) was $16.59 \pm 8.43 \mathrm{mV}$. According to NCV, 14 (22.22\%) patients had mild CTS, $19(30.16 \%)$ had moderately severe CTS and 30 (47.62\%) had severe CTS. Moon et al. in their study on 80 patients with CTS found that on nerve conduction study, the median nerve motor latency was $4.73 \pm 0.83 \mathrm{~ms}$ whereas sensory latency was $3.44 \pm 0.56 \mathrm{~ms}$. The median nerve palmar orthodomic sensory latency was found to be $2.57 \pm 0.31$ $\mathrm{ms}$. The conduction velocity across the palm and wrist was $41.37 \pm 0.67 \mathrm{~ms}^{17}$

Werner et al. conducted a study on 949 subjects of whom 261 had CTS. They found that only $16 \%$ of slender individuals were diagnosed with CTS compared to $39 \%$ of obese subjects. The relative risk for obese individuals compared to slender individuals was $2.5(95 \% \mathrm{CI}=1.4$, 4.2). The mean BMI for those individuals with CTS was
$28.9(6.8)$ and $26.2(6.0)$ in the remainder of the population. They concluded that individuals with a higher BMI are at increased risk for CTS, although the pathophysiology that would explain this relationship is not well understood. ${ }^{10}$ In the study by Becker et al. 791 CTS patients were studied, along with 1764 controls. The mean BMI was greater in the case group $(27.5 \pm 4.8)$ than in the control group $(25.2 \pm 4.1)(p>0: 0001)$. With respect to BMI, an increase in the frequency of CTS was seen with a BMI greater than 25; however, this difference was significant only when BMI was above $30 .{ }^{14}$ Stallings et al. found that obesity was associated with positive findings on nerve-conduction studies for median neuropathy (crude $\mathrm{OR}=3.92,95 \% \mathrm{CI}=2.65$ to $5.79, \mathrm{p}<.0000001)$. In their study, the average BMI of the study group (positive CTS) was $30.15+5.9$. The average BMI of the control group was $25.96+5.04$. The difference between the BMI measurements of the study and control groups was analyzed with a pooled t-test (two-tailed) and was found to be statistically significant $(\mathrm{p}<.001) .{ }^{18}$ Lam et al. compared $512 \mathrm{CTS}$ patients with normal controls and found that $80.95 \%$ of males in the CTS group were overweight compared with only $58.2 \%$ of males in the general population. The prevalence of obesity in males with CTS was more than twice the prevalence of obesity in men in the general population. The number of overweight female patients in their study (73.68\%) was more than twice that in females in the general population $(36.49 \%)$. The prevalence of obesity in females in their study (35.09\%) was also more than twice the prevalence of obesity in the general female population. ${ }^{19}$ In the study by Karpitskaya et al. the BMI was calculated for 378 CTS patients and 100 control subjects. In total, $72.0 \%$ of the CTS patients in their study were either obese or overweight; 140 patients $(37.0 \%)$ were obese with a BMI greater than $30 \mathrm{~kg} / \mathrm{m} 2$ and 131 patients $(34.7 \%)$ were overweight with a BMI between 25 and $29.9 \mathrm{~kg} / \mathrm{m}^{2}$. In the male CTS patient sample, 48 of 155 men were obese $(31.0 \%)$ and in the female CTS sample, 92 of 223 women were obese (41.2\%). There was a significantly greater percentage of obese subjects in the CTS group than in the control group $(p<0.02)$. The odds ratio for obesity and CTS was $1.77 .{ }^{15}$ Kouyoumdjian et al. in their study on 141 patients found that control subjects have a mean BMI of $25.43 \pm 4.80$ versus $28.38 \pm 4.69$ of all CTS cases, a statistically significant difference $(p<0.001) .{ }^{20}$ All these studies suggest that high BMI is associated with CTS, which is consistent with our findings. 
Of the 30 patients with severe CTS, only 1 was of normal BMI. Twelve patients were overweight, 13 obese and 3 morbidly obese. Among the patients with moderately severe CTS, 3 were of normal BMI, 9 were overweight, 6 obese and 1 morbidly obese. Only one of the patients with mild CTS was morbidly obese. Despite this, increasing BMI was not associated with severity of CTS. The study by Mansoor et al. found that according to BMI in the normal weight category, out of 78 patients, there were 14 patients with mild CTS, 33 patients with moderate CTS, and 27 patients with severe CTS. In the obese category, there were 6 patients with mild CTS, 21 patients with moderate CTS, and 11 patients with severe CTS. There were no statistically significant results observed between BMI and the severity of CTS $(p>0.05){ }^{8}$ The study by Kouyoumdjian et al. also had similar findings, where the CTS groups of increasing median sensory peak-latency severity did not show additional increase in BMI (28.44 for incipient, 28.27 for mild, 28.75 for moderate and 29.0 for severe).$^{20}$

\section{Limitations}

There were some limitations about the present study. The study was done in specialized hospitals in the capital city and does not reflect the picture of the entire country. Due to resource constraints, we could not perform all the investigations in the control group like serum vitamin B12 assay, X-ray cervical spine etc. Therefore, a small chance of presence of confounding factors remained in the controls. As purposive sampling technique was used, there was more chance of selection bias as this was non-probability sampling.

\section{Conclusion}

This study found that high BMI has a significant association with CTS. There is no association of increasing BMI with the severity of CTS. CTS was more common in females.

Authors' contribution: MMR, ZA, MMR, PKS conceived the idea and designed the analysis. ZA was in-charge for overall supervision. MM, MA, SMMHossain collected data. MAA, PKS contributed in organizing data. MAA performed the analysis. MMR drafted the manuscript. All authors read and approved final manuscript for publication.

Conflicts of interest: Nothing to declare.

\section{REFERENCES}

1. Atroshi I, Gummesson C, Johnsson R, Ornstein E, Ranstam J, Rosén I. Prevalence of carpal tunnel syndrome in a general population. JAMA 1999; 282: 153-8.

2. Paget J. Lectures on surgical pathology. Philadelphia 1854; Lindsay and Blakston.

3. Alfonso C, Jann S, Massa R, Torreggiani A. Diagnosis, treatment and follow-up of the carpal tunnel syndrome: a review. Neurolog Sci 2010; 31(3): 243-52.

4. Graham B, Peljovich AE, Afra R, Cho MS, Gray R, Stephenson J, et al. The American Academy of Orthopaedic Surgeons Evidence-Based Clinical Practice Guideline on: Management of Carpal Tunnel Syndrome. J Bone Joint Surg Am. 2016;98(20):1750-4.

5. Zyluk A, Kosovets L. An assessment of the sympathetic function within the hand in patients with carpal tunnel syndrome. J Hand Surg Eur 2010; 35(5): 402-8.

6. Nishimura A, Ogura T, Hase H, Makinodan A, Hojo T, Katsumi Y, et al. A correlative electrophysiologic study of nerve fiber involvement in carpal tunnel syndrome using current perception thresholds. Clin Neurophysiol 2004; 115: 1921-4.

7. Kang EK, Lim JY, Shin HI, Gong HS, Oh JH, Paik NJ. Comparison between nerve conduction studies and current perception threshold test in carpal tunnel syndrome. Neurophysiol Clin 2008; 38: 127-31.

8. Mansoor S, Siddiqui M, Mateen F, Saadat S, Khan ZH, Zahid M, et al. Prevalence of Obesity in Carpal Tunnel Syndrome Patients: A Cross-Sectional Survey. Cureus 2017; 9(7): e1519.

9. Ghali J, Murugasu A, Day T, Nicholls K. Carpal tunnel syndrome in fabry disease. JIMD Rep 2012; 2: 17-23.

10. Werner RA, Albers JW, Franzblau A, Armstrong TJ. The Relationship between Body Mass Index and the Diagnosis of Carpal Tunnel Syndrome. Muscle \& Nerve1994; 17: 632-6.

11. Ebrahimzadeh MH, Mashhadinejad H, Moradi A, Kachooei AR. Carpal tunnel release in diabetic and non-diabetic patients. Arch Bone Jt Surg 2013; 1: 23-7.

12. Geoghegan JM, Clark DI, Bainbridge LC, Smith C, Hubbard R. Risk factors in carpal tunnel syndrome. J Hand Surg 2004; 29B(4): 315-20.

13. Biswas T, Garnett SP, Pervin S, Rawal LB. The prevalence of underweight, overweight and obesity in Bangladeshi adults: Data from a national survey. PLoS ONE 2017; 12(5): e0177395.

14. Becker J, Nora DB, Gomes I, Stringari FI, Seitensus R, Panosso JS, et al. An evaluation of gender, obesity, age and diabetes mellitus as risk factors for carpal tunnel syndrome. Clinical Neurophysiology 2002; 113: 142934. 
15. Karpitskaya Y, Novak CB, Mackinnon SE. Prevalence of smoking, obesity, diabetes mellitus, and thyroid disease in patients with carpal tunnel syndrome. Ann Plast Surg 2002; 48: 269-73.

16. Ibrahim I, Khan WS, Goddard N, Smitham P. Carpal Tunnel Syndrome: A Review of the Recent Literature. The Open Ortho J 2012; 6(s1): 69-76.

17. Moon PP, Maheshwari D, Sardana V, Bhushan B, Mohan S. Characteristics of nerve conduction studies in carpal tunnel syndrome. Neurol India 2017; 65: 1013-6.
18. Stallings SP, Kasdan ML, Soergel TM, Corwin HM. A Case-Control Study of Obesity as a Risk Factor for Carpal Tunnel Syndrome in a Population of 600 Patients Presenting for Independent Medical Examination. J Hand Surg 1997; 22A: 211-5.

19. Lam N, Thurston A. Association of Obesity, Gender, Age and Occupation with Carpal Tunnel Syndrome. Aust NZ J Surg 1998; 68: 190-3.

20. Kouyoumdjian JA, Morita MDPA, Rocha PRF, Miranda $\mathrm{RC}$, Gouveia GM. Body mass index and carpal tunnel syndrome. Arq Neuro Psiquiatr 2000; 58(2A): 252-6. 